Research Article

\title{
Burning Rate Enhancement Analysis of End-Burning Solid Propellant Grains Based on X-Ray Real-Time Radiography
}

\author{
Wei Xianggeng $\mathbb{D}^{1}{ }^{1}$ Bo Tao, ${ }^{1}$ Wang Pengbo, ${ }^{2}$ Ma Xinjian, ${ }^{2}$ Lou Yongchun, ${ }^{2}$ and Chen Jian ${ }^{1}$ \\ ${ }^{1}$ Science and Technology on Combustion, Internal Flow and Thermal-Structure Laboratory, Northwestern Polytechnical University, \\ Xi'an 710072, China \\ ${ }^{2}$ Shanghai Space Propulsion Technology Research Institution, Shanghai 201109, China
}

Correspondence should be addressed to Wei Xianggeng; realysnow@nwpu.edu.cn

Received 15 February 2020; Revised 9 May 2020; Accepted 3 June 2020; Published 22 June 2020

Academic Editor: Angelo Cervone

Copyright ( $\odot 2020$ Wei Xianggeng et al. This is an open access article distributed under the Creative Commons Attribution License, which permits unrestricted use, distribution, and reproduction in any medium, provided the original work is properly cited.

Unexpected pressure rise may occur in the end-burning grain solid rocket motor. It is generally believed that this phenomenon is caused by the nonparallel layer combustion of the burning surface, resulting in the increase of burning rate along the inhibitor. In order to explain the cause of this phenomenon, the experimental investigation on four different end configurations were carried out. Based on the X-ray real-time radiography (RTR) technique, a new method for determining the dynamic burning rate of propellant and obtaining the real-time end-burning profile was developed. From the real-time images of the burning surface, it is found that there was a phenomenon of nonuniform burning surface displacement in the end-burning grain solid rocket motor. Through image processing, the real-time burning rate of grain center line and the real-time cone angle are obtained. Based on the analysis of the real-time burning rate at different positions of the end surface, the end face cone burning process in the motor working process is obtained. The closer to the shell, the higher the burning rate of the propellant. Considering the actual structure of this endburning grain motor, it is speculated that the main cause of the cone burning of the grain may be due to the heat conduction of the metal wall. By adjusting the initial shape of the grain end surface, the operating pressure of the combustion chamber can be basically unchanged, so as to meet the mission requirements. The results show that the method can measure the burning rate of solid propellant in real time and provide support for the study of nonuniform combustion of solid propellant.

\section{Introduction}

According to the requirements of the mission, the main working parameters design, propellant selection, and grain design of the solid propellant rocket motor are accomplished. Whether the actual measured parameters of the motor are consistent with the design value, the consistency of parameters of the motor will determine whether the mission requirements are met. However, the operating pressure of solid rocket motor with end-burning grain measured in experiments is often higher than the theoretical value. It has been possible to demonstrate that this phenomenon results from a nonuniform regression of the grain surface, which is in turn the result of the increase of propellant burning rate near the wall. A lot of research work on this phenomenon has been done, trying to explain the causes and formation process of this phenomenon. After the interrupted-burning test of the end-burning grain motor and the observation of residual propellant at the bottom of the combustion chamber, the plane end grain generated a conical in the combustion process [1]. Currently, the studies on pressure rise and burning regression of the end-burning motor are still inadequate [2]. It is generally believed that end-burning cone burning effect and pressure rise are affected by both physical and chemical mechanisms. And the physical mechanism mainly includes particle aggregation [3], shear flow [4], composition shift $[5,6]$, stress $[5,6]$, heat conduction effects [7], stressinduced grain defect [8], and end motor structure [9], while chemical mechanism mainly contains chemical reaction feature [10], heat flux of gas [11], and flame stretch by the velocity field [12]. In order to prevent the cone problem and interior ballistic instability from affecting the performance and reliability of a grain, the improvement in grain configuration [13], an important means of stabilizing the working 

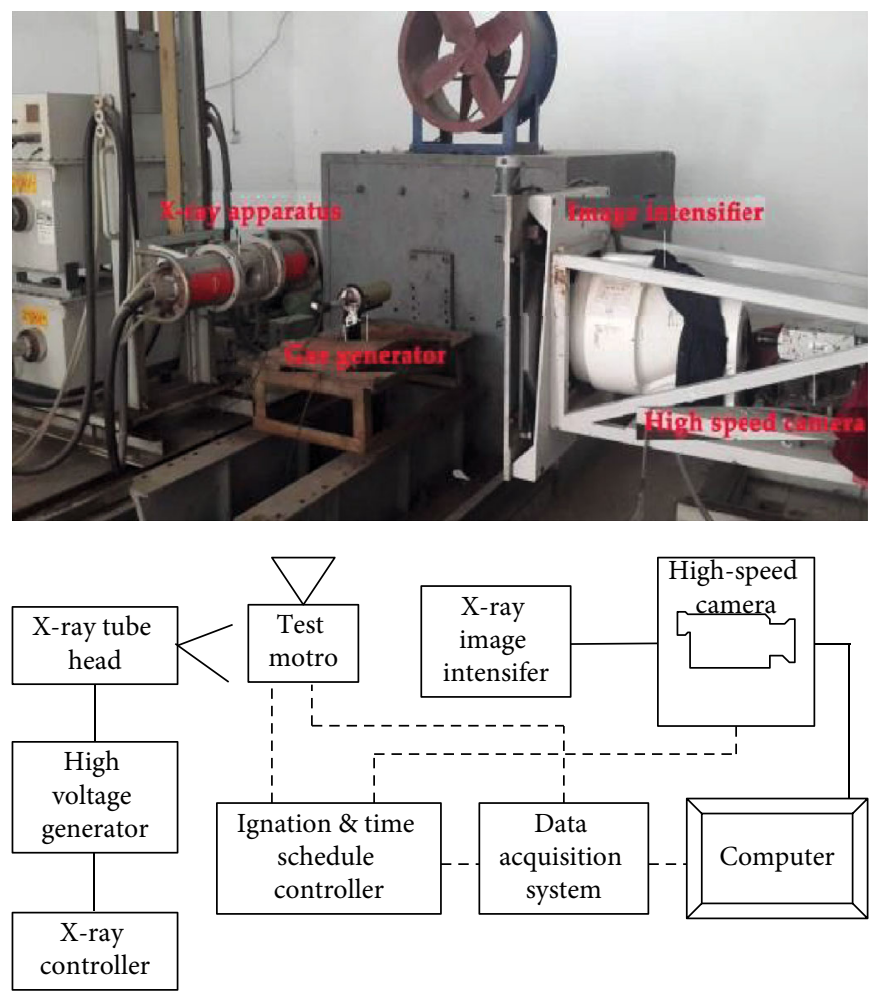

FIGURE 1: X-ray real-time radiography test system and layout.

pressure is often adopted. It is necessary to judge the feasibility of the modified design and its advantages and disadvantages in contrast with other designs and study the end-burning law.

X-ray real-time radiography (RTR) technique was developed in late 1980s [14] and has been used as a powerful tool to investigative the combustion process of rocket motor ignition tests. RTR is a noncontact diagnostic technique to study the complex working process in the highpressure burner or the motor [15-18]. The technical principle and basic system composition of RTR technique can be referred to Ref. 15. RTR technique has been successfully applied to the study of propellant burning rate test, crack growth, erosion combustion, nozzle erosion, two-phase flow, and so on $[15,18]$. RTR technique has become an important research method of solid engine technology development.

End-burning issues include a complex physical and chemical process thus to be analyzed in details. In the present work, the motors at the normal temperature are tested with multiple groups of grain with the same main geometric parameters and different initial end configurations. The dynamic burning regression of the grain under different initial end configuration conditions is also observed with RTR. The relationship between real-time grain configuration and burning rate as well as the change law according to the data of combustion chamber pressure is analyzed. The regression phenomena of nonparallel burning including the conical combustion of end-burning grain, the fringe effect, and the pressure rise are verified and discussed.

\section{Experimental System and Method}

2.1. X-Ray Real-Time Radiography. X-ray from a point source attenuates after photoelectric absorption, and the intensity is uniform when unattenuated X-ray reaches the image intensifier receiving screen [19]. According to BeerLambert Law, X-ray intensity distribution on the receiving screen reflects the medium attenuation, the change of medium thickness, and density on the X-ray path. Therefore, a grain burning regression process is suitable to study $\mathrm{X}$-ray technology [20].

Test system and layout are shown in Figure 1. The entire system mainly includes the X-ray generator, image intensifier, high-speed camera, test bench mobile control system, ignition/timing control, and data collection system. An $\mathrm{X}$-ray generator as the radiation source of X-ray realtime radiography system adopts the MXR-421/26 ray tubes manufactured by COMET of Switzerland, with an ray tube target angle of $20^{\circ}$ and an X-ray beam cone angle of $38^{\circ}$. The E5876HD industrial image intensifier of Toshiba with the resolution $46 \mathrm{lp} / \mathrm{cm}$ and the receiving screen size $300 \mathrm{~mm}$ is adopted, which can receive the X-ray penetrating through the grain and convert it to the optical signal easy to be collected by the high-speed camera. The high-speed camera PhantomV4.3 is adopted to collect the optical signal from the image intensifier and record the whole-process image sequence of end burning. For the purpose of the test, its resolution is set to $800 * 600$, the frame rate is set as 50 frames per second, and photo exposure time is set as 10 microseconds. The axis of the test motor should be kept 


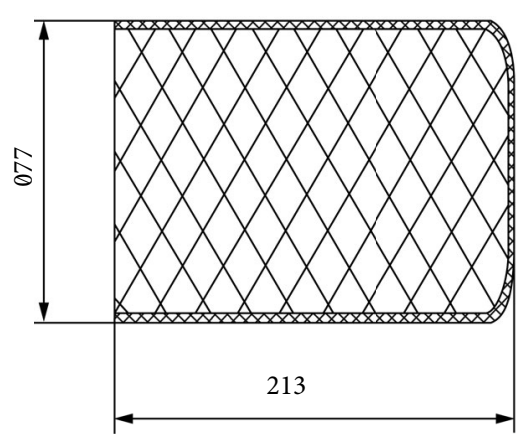

Test1

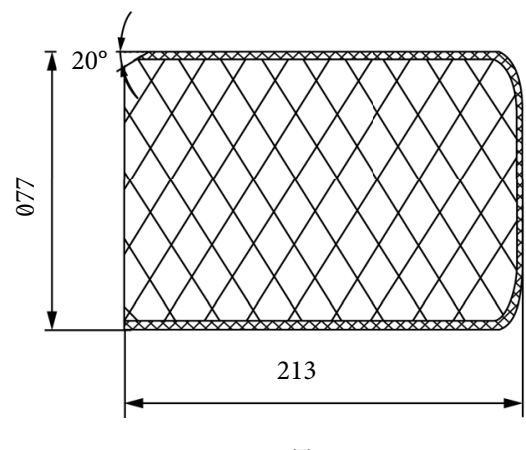

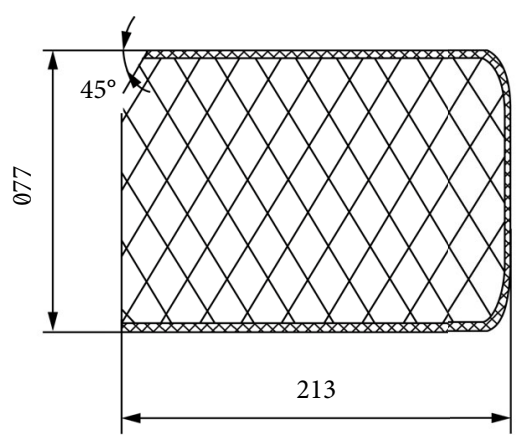

Test2

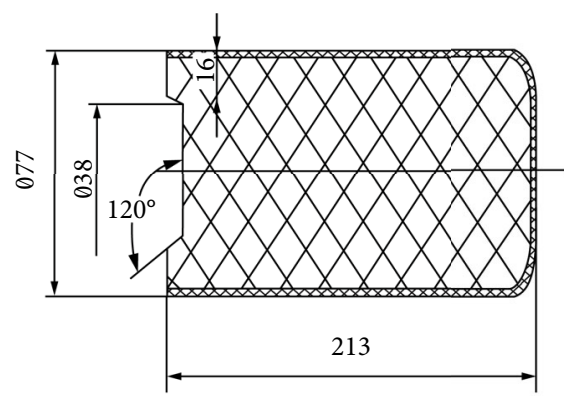

Test 4

Figure 2: Grain configuration.

TABLE 1: Main parameters of grain end.

\begin{tabular}{lcccc}
\hline & Test1 & Test2 & Test3 & Test4 \\
\hline$\alpha /^{\circ}$ & 0 (pure end) & 45 & 20 & 120 (circular groove angle) \\
Initial burning area $\left(\mathrm{mm}^{2}\right)$ & 4654.3 & 4859.14 & 5726.2 & 6464.6 \\
\hline
\end{tabular}

horizontal to ensure the data accuracy of the image. Also, before the experiment, standard elements are used to calibrate images. Then, the experiments are carried out and the combustion chamber pressure is measured.

2.2. Grain Configurations. In order to study the burning regression situation under different initial conditions, experimental tests on four different initial burning grain configurations and one plane end grain configuration are made. Grain ends for Test1-Test 4 are shown in Figure 2, and the main parameters of end surface of the grain are shown in Table 1. The basic parameters of the column are the same, the total length of the column is $213 \mathrm{~mm}$, and the diameter is $77 \mathrm{~mm}$. There are some differences in the initial combustion end face of the grain, and the specific differences are shown in Figure 2. The free-standing grain is adopted with the burning temperature of $1520 \mathrm{~K}$ and average molecular weight of 19 . The propellant contains ammonium nitrate (mass fraction of $82 \%$ ) and HTPB (mass fraction of 18\%) and the heat insulation layer of butadiene-acrylonitrile rubber. The propellant burning rate is calculated by the burning rate formula $r=1.33 p_{\mathrm{c}}{ }^{0.48}$.

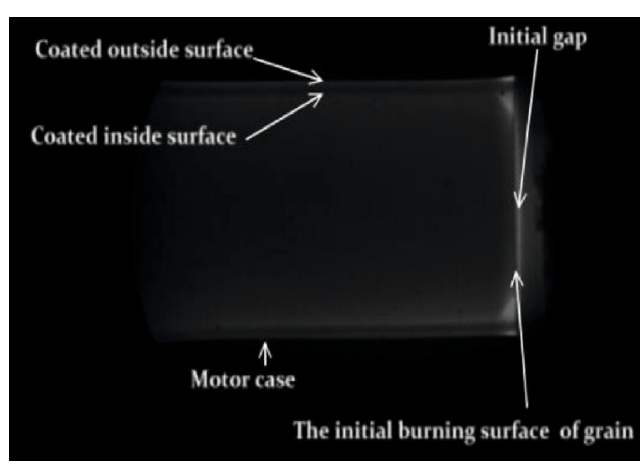

FIgURE 3: Static map of grain's initial imaging.

2.3. Image Processing Method. Figure 3 shows the captured image of Test2. As can be seen from the figure, the shape of the engine shell, grain, and end face is clear and visible.

The center line for the selected grain is designed after leveling of the motor case boundary with the bottom arc as the benchmark. The linear burning rate is defined as the 


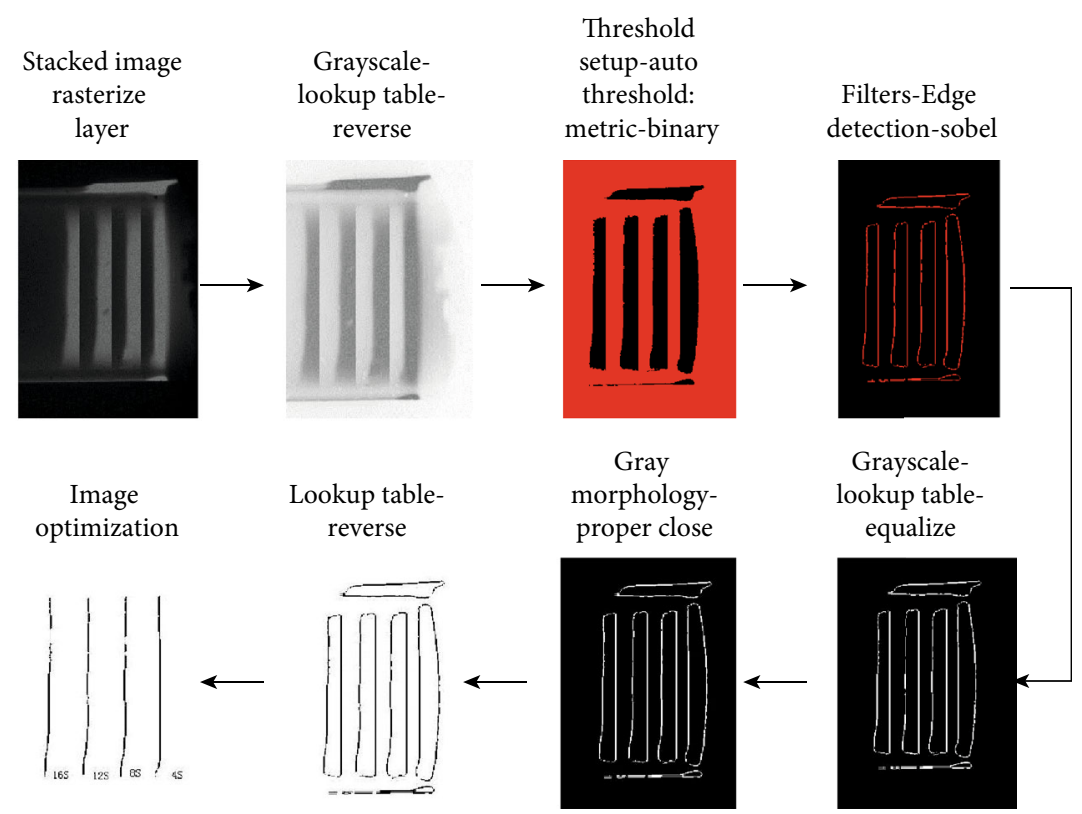

FIGURE 4: Procedures of image processing method.

distance of solid phase disappearance in the normal direction of grain per unit time and can be used to calculate the average burning rate and actual burning rate [21]. At the beginning of the test, the benchmark distance of the center line grain burning and the lateral imaging pixel value are measured. Throughout the test, the high-speed camera shooting frequency is fixed. Images were sampled every $0.5 \mathrm{~s}$, and the grain combustion situation, the changes in grain burning chamfer, and the dynamic, real-time imaging were analyzed for Test2, Test3, and Test4, respectively. In order to obtain the accurate burning rate of propellant, the high-speed photography time frames were measured, especially the key time frames with the nonuniform changes of end. The adjacent frames of key positions were selected for processing, and the average ratio between length and time was defined as the instantaneous average burning rate.

In order to obtain the end shape and burning rate of endburning grain better, it is necessary to extract the end shape and position of each moment from the image. Image processing software NI Vision Assistant 2012 is used in present study to extract the shape and position of the end shape. The specific image processes are shown in Figure 4.

\section{Test Results and Analysis}

In order to minimize the impact of other factors on the endburning law and interior ballistics [22], the same batch of propellants for the grains was adopted. Before the testing, all test motors were kept at a temperature of $298 \mathrm{~K}$ for 24 hours. Experiments were carried out at room temperature. The X-ray images and pressure data of Test2, Test3, and Test 4 and pressure data of Test 1 were collected. The images were processed by the image processing method in Section 2.3, and then, the instantaneous average burning rate and end chamfer of the grain were obtained, and the burning surface regression law and conical combustion effect were ana-
TABLE 2: Operating time and pressures of tests.

\begin{tabular}{lccc}
\hline & Operating time $(\mathrm{s})$ & $p_{\max }(\mathrm{MPa})$ & $p_{\text {avg }}(\mathrm{MPa})$ \\
\hline Test1 & 56 & 7.04 & 6.67 \\
Test2 & 58 & 6.60 & 6.38 \\
Test3 & 54 & 7.37 & 6.75 \\
Test4 & 62 & 7.22 & 6.25 \\
\hline
\end{tabular}

lyzed. According to the pressure-time curves of four test motors, the end-burning law and pressure rise effect were analyzed.

3.1. Interior Ballistic Performances. The pressure-time curves of gas generator chambers are shown in Figure 4.

Maximum pressures and average operating pressures of tests are obtained after the data processing, which are shown in Table 2.

As shown in Figure 5, the pressure reached a peak in the beginning of the test due to the action of ignition composition but became stabilized in very short time. Due to the difference in chamfer and configuration, their initial burning areas are different (Test $4>$ Test $3>$ Test $2>$ Test 1 ). In the early operating stage, the rates of pressure rise in combustion chamber were sequenced as Test $3>$ Test $4>$ Test $1>$ Test 2 . As clearly shown in the pressure-time curve of Test1, pressure rise phenomenon appeared in the stable operating stage, and the maximum operating pressure increased by $15 \%$. From the pressure time curve of Test2, it can be seen that the average pressure is $6.38 \mathrm{MPa}$, and the pressure changes in the range of $6.2 \mathrm{MPa}-6.6 \mathrm{MPa}\left(-2.8 \% p_{\text {avg }}\right.$ to $\left.3.4 \% p_{\text {avg }}\right)$. The overall pressure is stable, and the change range is small. In the stable operating stage of Test3, the pressure maintained a rising trend and increased by $16 \%$ compared to the initial operating pressure, which is higher than those of 


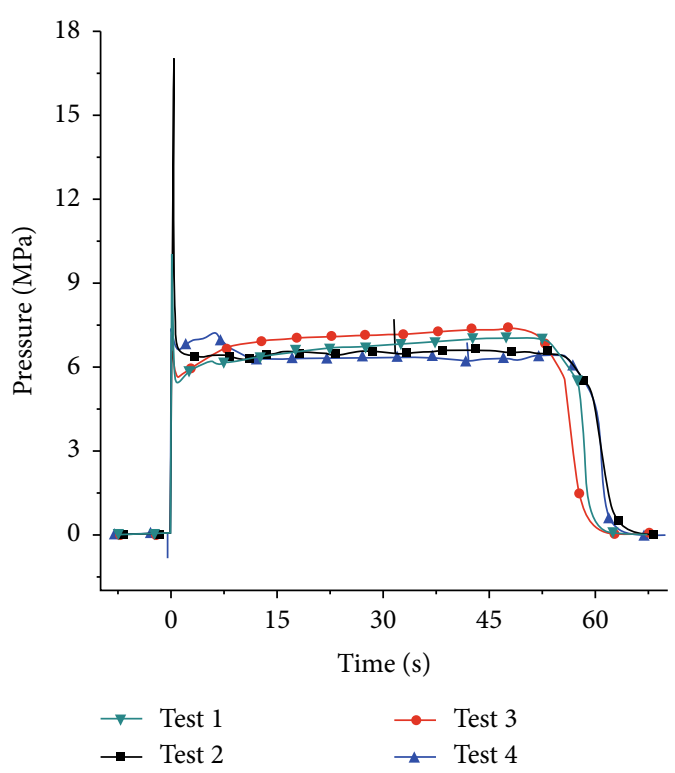

FiguRe 5: Pressure-time curve of test.

Test1. Due to the large initial burning area of Test4, the combustion chamber pressure reached the peak at $7 \mathrm{~s}$ and then kept stable after $10 \mathrm{~s}$ and until the end of combustion. According to Figure 5, the operating pressures of the Test1 and Test 3 were higher than that of the other two tests, and there was obvious pressure climbing phenomenon in Test1 and Test3. Compared to the roughly same operating time designed for Test 2 and Test 4 , the operating time for Test 1 is relatively short, while that of Test 3 is the shortest. According to $p_{\mathrm{c}}=\left(\rho_{\mathrm{p}} \bullet c^{*} \bullet a \bullet\left(A_{\mathrm{b}} / A_{\mathrm{t}}\right)\right)^{1 /(1-n)}$ and $p_{\mathrm{c}} A_{\mathrm{t}} / \mathrm{c}^{*}=\rho_{\mathrm{p}} A_{\mathrm{b}} r$, with the same propellant parameters and nozzle throat area, the chamber pressure increases with the increasing of burning surface area and burning rate. So the change of average burning rate and burning surface area will affect the change of the chamber pressure. For Test1, the initial burning surface is end burning, so the chamber pressure is constant according to the ideal state, but the actual pressure keeps climbing. This indicates that the burning rate or burning surface has changed during the working process. For solid rocket motor development, there are two main ways to solve this problem in practice. One method is to optimize the propellant formulation by obtaining the combustion characteristics of propellant and analyzing the reasons for the change of burning rate or burning surface area, which is timeconsuming and costly. Another method is to make the chamber pressure constant through the compensation design of the grain burning surface. In contrast, the second method can achieve the goal economically and quickly. In order to keep the constant working pressure, the compensation design of the grain burning surface is adopted in the present study. Different compensation burning surfaces were designed and tested to obtain the optimal compensation burning surface. According to Figure 5 and Table 2, the pressure stability of Test 2 is the best compared with other experiments. The dynamic burning rate was analyzed by using X-ray dynamic real-time image analysis to further

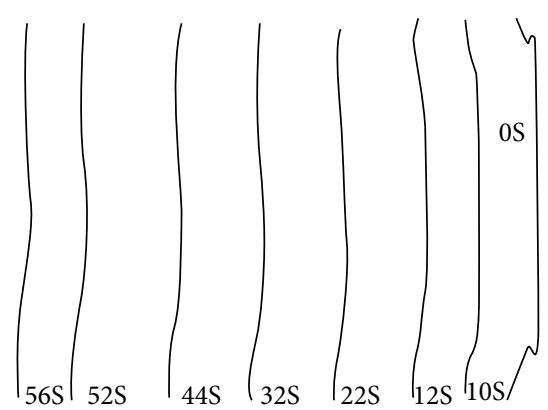

FIgURE 6: Imaging of grain end at each different moment of Test2.

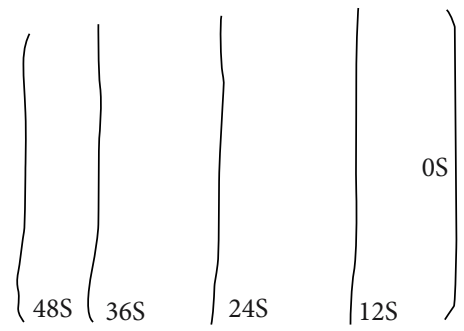

FIgURE 7: Imaging of grain end at each different moment of Test3.

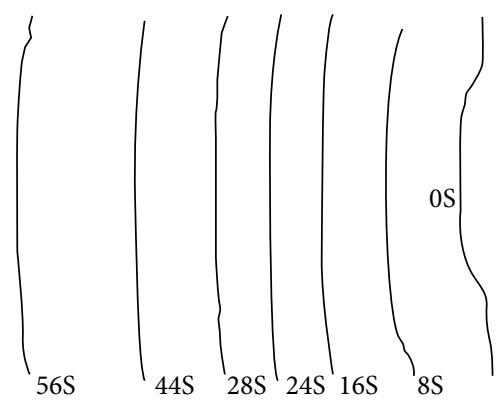

Figure 8: Imaging of grain end at each different moments of Test4.

analyze the cause of the rising of the chamber pressure and the effect of the compensation burning surface.

3.2. Analysis of Dynamic, Real-Time X-Ray Imaging. Imaging results show that the average burning rates of propellant for Test2, Test 3 , and Test 4 were $3.38 \mathrm{~mm} / \mathrm{s}, 3.56 \mathrm{~mm} / \mathrm{s}$, and $3.25 \mathrm{~mm} / \mathrm{s}$, respectively. The end imaging situation of grains at each representative moment of Test2-Test 4 is shown in Figures 6-8.

As shown in Figure 6, the grain chamfer structure exists at the initial moment that disappeared at about $12 \mathrm{~s}$. Burning regression was maintained stable in the subsequent combustion process, and combustion chamber pressure was kept stable without conical phenomenon. In the later operating process, the phenomenon of slight burning irregularity appeared. The combustion chamber pressure curve shows that the pressure always maintained stable in the stable operating stage. For the constant nozzle throat area, it can be seen that grain end always maintained a relatively constant 
burning surface from $0 \mathrm{~s}$. At the end of operating stage (about $56 \mathrm{~s}$ ), the end was not arc-shaped, and there was few residual grain. In general, the phenomenon of slight grain endburning irregularity happened in the case of Test2, the burning regression in the combustion process was stable, and no phenomenon of observable conical combustion appeared at the end of combustion process.

As shown in Figure 7, grain burning surface of Test 3 was smaller than those of Test 2 and Test 4 at $0 \mathrm{~s}$, and the combustion chamber pressure reached the minimum at the same time. After firing, the pressure continuously rose. In particular, the end surfaces at $12 \mathrm{~s}$ and $24 \mathrm{~s}$ are different: there was basically a plane burning surface at $12 \mathrm{~s}$, while the marginal burning rate was larger than the center burning rate at $24 \mathrm{~s}$. Throughout the operating stage, progressive burning phenomenon existed, the propellant burning rate near the motor case edge was greater than the burning rate of grain center, and the burning combustion was uneven. At the end of the combustion process, the end surface looked slightly convex and arc-shaped with more residual propellant. In general, under the conditions of Test3, the grain end-burning fringe effect was very obvious, the progressive burning phenomenon happened after disintegration of burning initial configuration, and the cone phenomenon and pressure rise phenomenon near the case were obvious in the end of combustion.

As shown in Figure 8, the end configuration was complex at $0 \mathrm{~s}$, and the burning was maintained stable after the increase and decrease successively. As seen from end surfaces of more coherent key frames, the burning change under the conditions of Test 4 was relatively regular, and there was minimum residual propellant at $56 \mathrm{~s}$, as shown in the corresponding figure. In general, besides the initial man-made nonneutral burning, the plane parallel layer combustion basically was the dominating grain end-burning way for Test4. Regressive burning followed progressive burning after the start of combustion, and relatively neutral burning phenomenon occurred in the stable operating stage, without pressure rise or conical combustion effect.

The grain combustion length along the center line per unit time was defined as the instantaneous average burning rate. The changes in the average burning rate and grain chamfer along with time are shown in Figure 9. According to the real-time pressure curve of motor in Figure 9, under the conditions of Test 2 , the combustion chamber pressure quickly became stable from a high point after the occurrence of the ignition peak. Throughout the operating process, burning rate, pressure, and burning area are all kept stable; however, the burning was slightly irregular and nonplanar. At the last stage of combustion, chamfer and burning area were basically kept stable; at the end of combustion, there was a small amount of residual propellant at the case bottom. Under the conditions of Test3, the combustion chamber pressure rapidly rose to the operating pressure from a lower point after the occurrence of the ignition peak. In the operating stage, the average burning rate was maintained stable, chamfer was slowly fluctuated and declined, and a very obvious fringe effect was generated. The average burning rates were compared, respectively, at the lower edge of the case
(9 $\mathrm{mm})$ and the center line in the time frame 20-36s. As shown in Figure 10, the propellant burning rate near the case was greater than that at the center, and progressive burning phenomenon was observed. In the second half of the operating period, the burning rate declined and then maintained stable until the end, and the pressure rose and decreased alternately. In the end of combustion, chamfer decline slowed down, and conical combustion weakened. Under the conditions of Test4, due to the setting of the end circular groove, the initial structure was decomposed $8 \mathrm{~s}$ later after the ignition peak, the combustion chamber pressure declined after rise, regressive burning followed the progressive burning, and finally, stable operating started. As there was no obvious fringe effect in the whole combustion process, an obtuse angle in the groove was used to measure the burning change. In the first half of the operating stage, the burning rate at the center line was maintained low stably, and the measured obtuse angle was continuously enlarged. In the second half of the combustion process, the burning rate continued to be kept stable, the measured obtuse angle fluctuated slightly in the vicinity of the flat angle, and the burning shape and area both maintained stable, without any phenomenon of conical combustion or pressure rise.

According to Figures 9(a), 9(c), and 9(e), the change of the burning rate at the center line of grain is small, and it was kept constant basically. In combination with the burning rate of the grain at different positions of the burning surface in Figure 10, it can be seen that the burning rate of the grain near the motor shell increases obviously, and it has a certain degree of nonuniformity in the whole process. These results show that the increase of chamber pressure is caused by the inconsistency of the burning rate of grain burning surface; in other words, the burning rate near the shell is larger than those of the center. What causes the burning rate of the grain near the shell to be greater than that at the center line of the grain? The propellant of the motor is low temperature and low burning rate propellant, and the motor shell is a metal shell without insulation, and the working time is about 60 seconds. From Figure 10, it can be seen that the burning rate near the shell is greater than that at the center line of the grain, which occurs after the motor working for a period of time, and the burning rate at the shell first increases slowly and then basically stabilizes and keeps a constant difference with the burning rate at the center line. After ignition, the high-temperature gases were generated, which transfer heat to the shell and the grain. The heat transfer of the metal shell is faster than that of the propellant itself. Therefore, the shell will transfer heat to the propellant close to the shell, and the heat will also be transferred to the propellant far from the burning surface and closer to the shell. This will change the burning rate of the propellant. It can be inferred that the heat transfer between the shell and the grain is the main process during the period when the burning rate does not change. After the heat transfer reaches a stable level, the burning rate of the two places is basically stable, which shows a basically constant difference phenomenon. Therefore, it is possible that the heat transfer of the shell results in an uneven burning rate. 

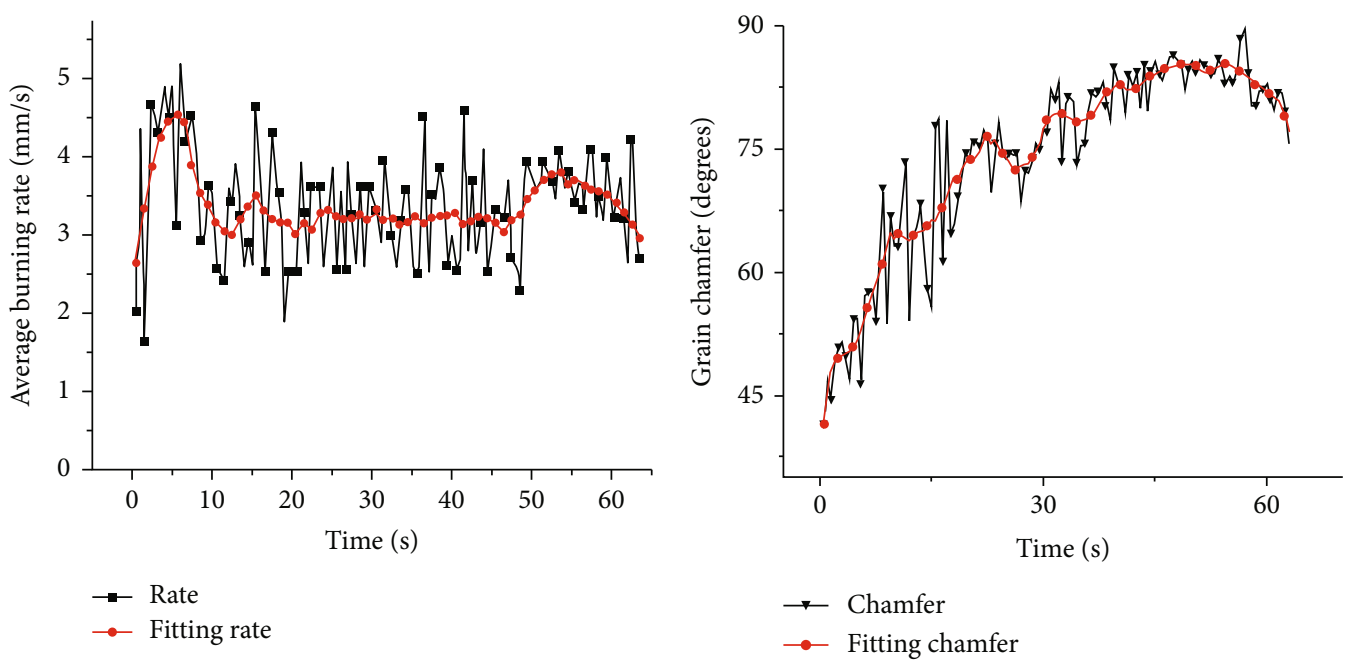

(a)

(b)
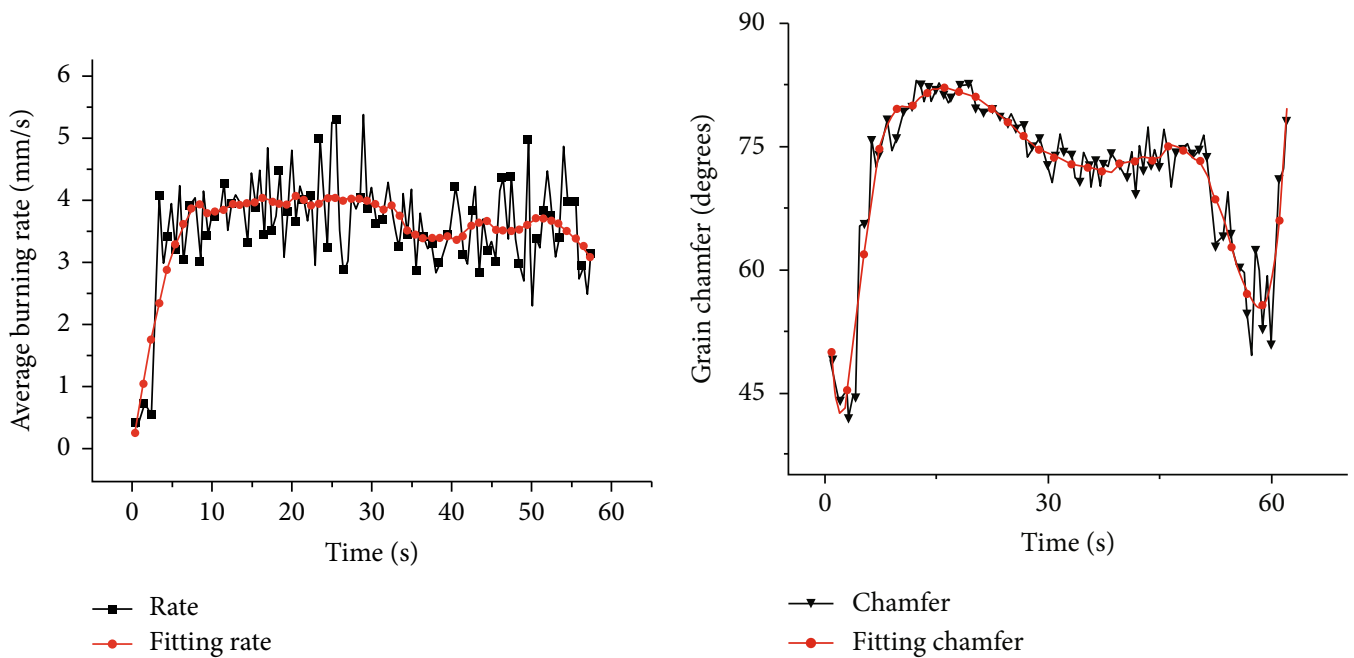

(c)

(d)

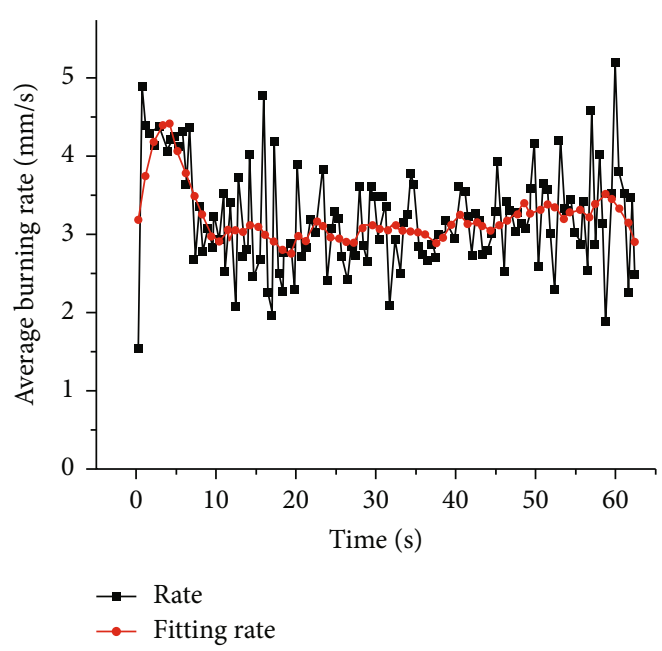

(e)

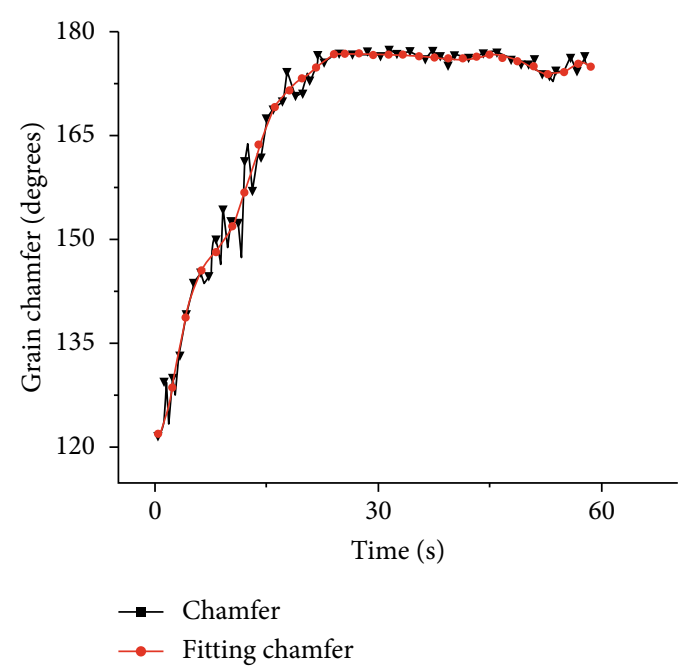

(f)

FIGURE 9: Time-based changes in grain chamfer and average burning rate of center line. (a), (c), and (e), respectively, represent the curves of time-based changes in the average burning rate of the center line for Test2, Test3, and Test4; (b), (d), and (f), respectively, represent the curves of time-based changes in the chamfer for Test2, Test3, and Test 4. 


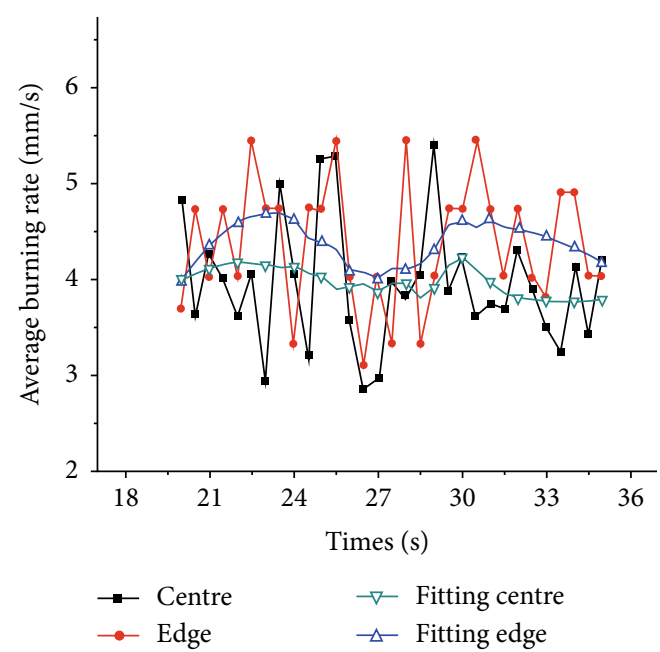

Figure 10: Average burning rates at the center line and the edge from 20 s to $36 \mathrm{~s}$ for Test3.

\section{Conclusion}

The X-ray real-time radiography experimental technique is used to study the nonparallel layer combustion of the endburning grain solid rocket motor. The development process of the nonparallel layer combustion, the change rules of end-burning rate, and end shape are obtained. The causes of the nonparallel layer combustion are analyzed. The reason for the cone burning is that the burning rate of the propellant near the shell is higher than that at the center line. For the end-burning grain solid rocket motor used in this paper, the nonparallel layer combustion may be caused by the rapid heat conduction of the metal shell. Three design methods of grain end face to improve performance and reduce the influence of the nonparallel layer combustion are evaluated, and the optimization scheme is obtained. From the experimental results, the scheme of $\alpha=45^{\circ}$ is the best one.

\section{Nomenclature}

2D: Two dimension

HTPB: Hydroxyl-terminated polybutadiene

$\alpha$ : Angle of the chamfer

$r$ : $\quad$ Burning rate of the propellant

$p_{c}: \quad$ Pressure of the gas generator chamber

$p_{\max }: \quad$ Maximum pressure of the gas generator chamber

$p_{\text {avg }}: \quad$ Average pressure of the gas generator chamber

$\rho_{\mathrm{p}}: \quad$ Density of propellant

$c *$ Characteristic velocity

$a$ : Burning rate coefficient

$A_{\mathrm{b}}$ : $\quad$ Burning surface area

$A_{\mathrm{t}}: \quad$ Area of the nozzle throat

$n$ : $\quad$ Burning rate pressure exponent.

\section{Data Availability}

All test data used during the study are available from the corresponding author by request.

\section{Conflicts of Interest}

The authors declare that they have no conflicts of interest.

\section{Acknowledgments}

Xianggeng Wei is sponsored by China Scholarship Council and Top International University Visiting Program for Outstanding Young Scholars of Northwestern Polytechnical University.

\section{References}

[1] T. L. Jackson, J. Zhang, and V. Topalian, "Erosive burning of solid propellants," in 48th AIAA Aerospace Sciences Meeting Including the New Horizons Forum and Aerospace Exposition, Orlando, Florida, Jan 2010AIAA Paper 2010-616.

[2] B. Gonthier and J. M. Tauzia, "Burning rate enhancement phenomena in end-burning solid propellant grains," in 21st Joint Propulsion Conference, Monterey, California, July 1985AIAA Paper 1985-1435.

[3] A. M. Messner, "Transient coning in end-burning solid propellant grains," in 16st Joint Propulsion Conference, Hartford, Conn., June 30-July 2, 1980AIAA Paper 1980-1138.

[4] V. D. Topalian, J. Zhang, T. L. Jackson, and A. H. G. Isfahani, "Numerical study of erosive burning in multidimensional solid propellant modeling," Journal of Propulsion and Power, vol. 27, no. 4, pp. 811-821, 2011.

[5] H. W. Jolley, J. F. Hooper, P. R. Hilton, P. R. Hilton, and W. A. Bradfield, "Studies on coning in end-burning rocket motors," in 21st Joint Propulsion Conference, Monterey, California, 8-10 Jul. 1985AIAA Paper 1985-1179.

[6] W. H. Jolley, J. F. Hooper, P. R. Hilton, and W. A. Bradfield, "Studies on coning in end-burning rocket motors," Journal of Propulsion and Power, vol. 2, no. 3, pp. 223-227, 1986.

[7] J. Moss, S. Heister, and K. Linke, "Experimental program to assess erosive burning in segmented solid rocket motors," in 43rd AIAA/ASME/SAE/ASEE Joint Propulsion Conference and Exhibit, Cincinnati, OH, 8-11 Jul. 2007AIAA Paper 2007-5782.

[8] C. T. Liu, "Monitoring microstructural evolution, crack formation, and damage characteristics near crack tip in a highly filled elastomer-using digital radiography X-ray techniques," Experimental Mechanics, vol. 47, no. 1, pp. 79-85, 2007.

[9] M. R. Z. Sheikholeslam, D. Kazemi, and H. Amiri, "Experimental analysis of the influence of length to diameter ratio on erosive burning in a solid tubular propellant grain," Applied Mechanics and Materials, vol. 110-116, pp. 3394-3399, 2011.

[10] S. Han and C. Kim, "Integrated fluid-structure simulation for full burning of a solid-propellant rocket interior," Journal of Propulsion and Power, vol. 30, no. 4, pp. 883-900, 2014.

[11] K. Srinivasan, S. Narayanan, and O. P. Sharma, "Numerical studies on erosive burning in cylindrical solid propellant grain," Heat and Mass Transfer, vol. 44, no. 5, pp. 579-585, 2008.

[12] J. Zhang and T. L. Jackson, "A model for erosive burning of homogeneous propellants," Combustion and Flame, vol. 157, no. 2, pp. 397-407, 2010.

[13] G. L. Mejia, R. J. Rocha, L. R. Jr et al., "Solid rocket motor burn simulation considering complex $3 \mathrm{D}$ propellant grain geometries," in 52nd AIAA/ASME/SAE/ASEE Joint Propulsion 
Conference and Exhibit, Salt Lake City, UT, 25-27 Jul. 2016AIAA Paper 2016-5098.

[14] P. Liaw, Y. Chen, and H. Shang, "Particulate muti-phase flowfield calculation with combustion/breakup models for solid rocket motor," in 30th Joint Propulsion Conference and Exhibit, Indianapolis, IN, 27-29 Jun. 1994AIAA Paper 19942780.

[15] D. A. Jones and R. A. Frederick, "Overview of X-ray techniques for solid rocket propellant regression measurements," in 52nd AIAA/ASME/SAE/ASEE Joint Propulsion Conference and Exhibit, Salt Lake City, UT, 25-27 Jul. 2016AIAA Paper 2016-4725.

[16] Y. Xiao, R. S. Amano, T. Cai, J. Li, and G. He, "Particle velocity on solid-propellant surface using $\mathrm{X}$-ray real-time radiography," AIAA Journal, vol. 41, no. 9, pp. 1763-1770, 2003.

[17] G. He, M. Liu, Y. Xiao, and T. Cai, "Edge detection technology for experimental diagnosis in rocket motor," Journal of Propulsion Technology, vol. 19, no. 2, pp. 105-108, 1998.

[18] G. Gupta, L. J. Mehilal, and B. Bhattacharya, "Various methods for the determination of the burning rates of solid propellantsan overview," Central European Journal of Energetic Materials, vol. 12, no. 3, pp. 593-620, 2015.

[19] A. Pogany, D. Gao, and S. W. Wilkins, "Contrast and resolution in imaging with a microfocus X-ray source," Review of Scientific Instruments, vol. 68, no. 7, pp. 2774-2782, 1997.

[20] M. D. Denny and R. A. Frederick, "Using real-time radioscopy to measure the burning rate of solid rocket motor propellant," in 51st AIAA/ASME/SAE/ASEE Joint Propulsion Conference and Exhibit, Orlando, FL, 27-29 Jul. 2015AIAA Paper 20154104.

[21] S. J. Song, H. J. Kim, S. F. Ko et al., "Measurement of solid propellant burning rates by analysis of ultrasonic full waveforms," Journal of Mechanical Science and Technology, vol. 23, no. 4, pp. 1112-1117, 2009.

[22] A. Javed and D. Chakraborty, "Universal erosive burning model performance for solid rocket motor internal ballistics," Aerospace Science and Technology, vol. 45, pp. 150-153, 2015. 